laboratory a number of tubes of radium of varying aegrees of radio-activity, and sample tubes of poloni-
um of both bismuth-polonium metal and nitrate of bismuth and polonium, each possessing a radio-activ ity 300 times that of uranium, and tubes of pitchblende, uranium, uranium residues from which the radium is esting set of photographs made by radium rays.

\section{DEVELOPMENT OF THE CERAMIC ART IN
CHINA.}

By Randolph I. Geare.

OLD Chinese legends contain statements to the effect that porcelain had been made in that country before years before the Christian era. Later legends refer to an official "directior of pottery" and to the difference between molding and fashioning with the pot
ter's wheel, which latter originally came from Korea. Sacrificial wine-jars, altar-dishes, coffins, cooking uten-
sils, etc., were among the articles produced. sils, etc., were among the articles produced.
It has long been determined, however,

earthenware could have been then made, nor can it be claimed that the manufacture of real porcelain
$\left(t z^{\prime} u\right)$ antedated the Han dynasty (B. C. 202 to A. D. $220)$. It is true that some porcelain bottles, decorated been found in undisturbed Egyptian tombs at least 1,800 years B. C., but proof that seems conclusive has been furnished, showing that the inscriptions were later these same inscriptions were identified as quotations from poems

The opinions of two eminent authorities on this point are of interest and importance. M. Julien has expressed his belief that true porcelain was first manu-
factured in China between the years $185 \mathrm{~B}$. C. and 87 A. D., while M. du Sartel, who published an exhaustive work on Chinese ceramics, places the date
turies later, i. e., during the T'ang dynasty.

But however this matter of date may be, whether during the Han or T'ang dynasty-and the point is question that no specimens manufactured previous to the Sung dynasty ( 960 to 1259 A. D.) have survived
to the present day, and the vexed question is therefore to the present day, and the vexed question is therefore
largely one of historical importance. Furthermore, the productions of the finer kinds even in the Sung
dynasty have entirely disappeared. Those which have survived are said to be only "céladons" of considerable word céladon," writes Mr. Hippisley, "was originally the name of the hero in the novel 'L'Astree,' written during the sixteenth century. This hero was attired in clothes of a kind of sea-green hue with gray or bluish tint, and his name was subsequently applied
to the clothes he wore." The Chinese equivalent of
the word is "ch'ing," which is applied to the colors of the word is "ch'ing," which is applied to the colors of porcelains of a blue, or a pale dull green."
Before discussing the principal characteristics of the porcelains made under the various dynasties, brief chinese porcelain, the method of shaping the paste, applying the glaze, and baking and decorating the objects, and it is but proper to add that the statements
are largely derived from the catalogue of Mr. Alfred E. Hippisley, a recognized authority on the subject, who has for many years been connected with the Im-
perial Maritime Customs Service of China, and whose perial Maritime Customs Service of China, and whose
collection of Chinese porcelains is now on exhibition in the National Museum at Washington

Porcelain consists of two essential parts: one in-
fusible, the fusible, the other fusible. The former is the paste
(pâte), which forms the body of the object; the latter is the glaze, which gives transparency, and prevents porousness or the possibility of the object contracting
under the influence of heat. The paste, which may be hard or soft, is made up of clays. These are classbility. The best of them is kaolin; which is a white aluminium silicate produced by the decomposition of granitic or feldspathic rocks, and is almost infusible.
The soft paste contains limestone products or alkalies, which lower its degree of fusibility, so that it 800 deg. Centigrade.

The crude kaolin, when freed from all impurities and ready for use in making the paste, gives a very white glaze for the hard Sèvres, is found in abundance at turned and molded when in a malleable state. It is not cast, as in Europe, and therefore the skill of the Chinese in shaping with the hands large jars and cups
as thin as egg-shell is all the more astonishing. They also seem not to have learned the advantage of bakfact that porcelain is dilutable by water (although cient to turn it red) furnishes an easy method of cient to turn it red) furnishes an easy method of be covered with a uniform layer of glaze by simply immersing it in water bearing in suspension the finely crushed material, provided that the proportions of water and glaze (with relation to the thickness of
the vessel to be covered) have been fully determined. The glazes used in China are for the most part compounded from substances whose proportions vary accrystalline mixture of quartz and feldspar) is seldom ible, and in some cases represents as much as onefourth of the total weight. Fern leaves also somewhat purpose they serve has not been fully ascertained.
Being ignorant, as already intimated, of the plan of subjecting the porcelain to a preliminary baking (unfer which the vessel, on account of its thus be-
coming less porous, may be immersed into the liquid coming less porous, may be immersed into the liquid immersion," or else by "insufflation." In the first of these processes the vessel is held by the outside slant-
ing over a basin containing the liquid glaze. Enough ing over a basin containing the liquid glaze. Enough surface. The outside is then immersed in the liquid. In employing insufflation, a piece of gauze is first at the glaze, the operator scatters the liquid over the vessel by blowing through the opposite end of the tube of which is covered with a thick layer of gravel. O this the "seggars," which are vessels of some refractory material that hold the pieces of porcelain, are
piled. The object of the "seggars" is to prevent the pieces from coming into direct contact with the flame or gases. The pieces are still soft and must be placed
in the seggars with great care, a contrivance of cords in the seggars with great care, a contrivance of cords
and sticks being used for the purpose. Then the piles of the oven are shut. A low fire is kept up during the first twenty-four hours, after which the heat is in creased. When the porcelain is sufficiently bakedand this is ascertained by applying a pair of pincer ered up during the baking-firing is stopped and al openings are closed

In China the coloring processes used in decoratin
ples the operation. porcelain are two-fold: colors du grand feu and colors the glaze is made with a brush on the unbaked porce lain, the coloring matter being peroxide of cobaltiferous manganese. Other colors, such as céladon and red grounds, also seem to be used, although some authorities consider their production, in China at least, as due to accident rather than design. The fond laque
or feuille mort is obtained by the use of oxide of iron. Black grounds are produced in a variety of ways either by the thickness of the colored glaze, or by lay or, again, by laying a blue glaze on a brown laque, o blue, yellow, and green grounds are applied on the porcelain after it has been fired at a high temperature. All of these colors contain a rather large proportion of oxide of lead. The green and turquoise blue ow their colors to the presence of copper; the yellow to manganese containing only a little cobalt

In Europe colors de moufle are obtained by mixin one oxide or several metallic oxides together in a vitreous flux, the composition of which varies with the
nature of the color to be developed. In China, on the nature of the color to be developed. In China, on the
contrary, the oxides are dissolved, which has the ef contrary, the oxides are dissolved, which has the ef position of which varies, according to the amount of fusibility required. Blues are supplied by oxide of cobalt; greens, by protoxide of copper; and reds, by color and opacity either to antimony, or to arsenic or
stannic acid. In European porcelains these were found to scale off; but this is not the case when placed on Chinese porcelains. This is explained by the fact that the paste of Chinese porcelain being more fusible than the European, the glaze must also be more eas for closer thion with the compounds forming the enamel. matter, and they are of but little value unless applied in a depth which gives the.painting a relief that can the decorations thus obtained, res.

and composition of the enamels. Commencing with the Sung dynasty ( 960 to 1259
A. D.), earlier than which there are probably no pieces A Chinese porcelain extant, the ware manufacture ing perhaps one kind; and it is worthy of note that prior to this dynasty the external color of all porcelain was apparently determined by that of the glaze. In most cases only one color was used, while in a few in stances vases were covered with parti-colored glaze another in the kiln, thus forming by accident a class
of objects whose decoration changed during the proof objects whose decoration changed during the pro-
cess of baking. The shapes and ornamentation apcess of baking. The shapes and ornamentation ap-
pear to have been copied from ancient bronzes, or else the vessel took the form of some natural object. The principal porcelains made during this dynasty are
the Ju-yao or Juchou, Kuan-yao, Ting-yao, Lungch"uan, Ko-yao or Chang-yao, Chün-yao, and many other of less prominence.

The finest specimens of Juchou, usually very thin were delicate plates and bowls, with either plain or the paste. A perfect vase of this period is considered almost unique and exceedingly valuable.

The Kuan-yao was the official porcelain, and wa made at the imperial factories between 1107 and 1117 . pale bluish-green; and others, dark green. Later pale in tint. This porcelain was very thin and sometimes was crackled so finely as to resemble a crab'

Ting-yao porcelain was of two kinds-Pei-ting an Nan-ting (Northern Ting and Southern 'Bing). The were brilliant white, purple, or black.

In the Lungch'-uan porcelain, the ornamentation was under the glaze, the shades of which varied from
the color of grass to a deep onion green, with occasithe color of grass to a deep onion green, with occasi-
onal bands of foliate or scroll pattern of a deeper tone two brothers, Chang by name, gained a high reputation for their porcelain, which was made at a factory in the Lungch'-uan district; but in separate kilns Ko-yao, while the ware of the younger brother was known as Chang-yao. Both were céladon in color, been that the Ko-yao was crackled, while the othe kind was not.

Chün-yao porcelain was sometimes molded in gro- tesque form, but was usually fashioned after ancient uronzes and ornamented with scroll or floral patterns two or more colors of glaze on the same vase. 1260 to 1349 , the manufacture of porcelain seems to have fallen behind, excepting in the case of objects produced for the special use of the Emperor, while in the Ming dynasty (1368 to 1649), there was made considerable progress in the ceramic art, both in the fineness of the ware as well as in the excellence of the that the ornamentation of vases with arabesques and scroll-work, with landscapes,
has been commonly ascribed.

has been commonly ascribed.
Decoration in many colors came to be more highly prized, and designs were obtained from the brushes of the best artists, which were afterward transferred to the porcelain by the most skilled workmen. The this dynasty, so far as the porcelain industry is con-
cerned. Then followed the Yunglo period (1403 to $1424)$, during which much white porcelain, with orna-
mentation in blue under the glaze, was manufactured. mentation in blue under the glaze, was manufactured. been brought from some Mohammedan country as tribute, and hence was known as "Mohammedan blue." Eggshell porcelain of very delicate workmanship was
now produced. The Chinese call it " $t$ 'o-t'ai," or pornow produced. The Chinese call it " $t$ 'o-t'ai," or por-
celain from which the "embryo" or biscuit has been Next in order is the Hsuantê period (1426-1435), and among the porcelain of this period the kind which was covered with crimson glaze, or bore designs in
that color, is said to hold the highest place in the eyes of Chinese connoisseurs. Another style of decoration was "three red fish on a white ground pure fresh blood, of a brilliant color dazzling the eyes." Still rarer styles of decoration were three pairs of
peaches in red on a white ground, and a "white ground ecorated inside and outside with cloud scrolls engraved in the paste, a scroll border above colored in high relief coiled round the top, with teeth and four claws fixed in the rim, enameled vermilion red." During the Chenghua period (1465-1487) the pro-
duction of blue porcelain, bearing a blue decoration under the glaze, continued, but the supply of blue from abroad had become exhausted, and for this reatation in enamel colors, this ware was inferior in more periods in this dynasty: The first was Hungmost in vogue, although enameling in color was also employed. The second was Chêngtê (1506-1521), in which period decoration in enamel colors continued, obtained, which caused attention to be again turned to the production of porcelain ornamented with blue
under the glaze. In this period also a curious kind of earthenware was made. Teapots of this ware were of a light brown or covered with a vermilion glaze.
The third was Chiaching (1522-1566), during which the yellow glaze was abandoned, and decoration in tion in blue under the glaze was chiefly admired, and to the present day the "blue and white" of this period (1573-1619). It now had become difficult to find good clays, and this fact, combined with increasing political disorders throughout the empire, caused a marked deterioration in the quality of the ware produced, although good workmanship was sometimes effected, the "millet grains," or a surface marked as with the pittings on orainge peel.

The Ming dynasty was now at an end, and with the factories at Chingtê-chên, which had been closed for some years, were renpened when the Manchu emperors reign of K'anghsi (1662-1722). This emperor and his two successors, Yungchêng (1723-1735) and Chienlung (1736-1795), advanced the ceramic art to the utmost degree. The ablest artists were employed, and to a high level of proficiency. So rapid was the progure and decoration of porcelain in China attained a degree of excellence probably never reached before or Green was the predominating color for decoration during the early part of K'anghsi's reign, and hence porcelain. Later, green gave way to red, and a style of half tints and broken colors with a base of carmine to pale rose was the distinguishing feature. With
the addition of yellow derived from antimony, and
white from arsenical acid, the variety and beauty of the decorations were greatly increased.
In 1727, after Yungchêng came to the throne, Nien Hsi-yao was made director of the imperial manufactories. His products, known as Nien porcelain, were chiefly monochromes, of blue, bright and carmine reds, céladons, and "of egg color as bright as
silver." The monochrome vases became extremely fashionable, and one small vase, only eight inches high, was not long ago sold in New York. for fifteen thousand dollars. After Nien Hsi-yao had had charge
for fifteen vears. T'angying succeeded him. and the obiects made under his orders were remarkable for delicacy of workmanship, purity of form and brillicoloring. He is also credited with the invention of several new styles of decoration, such as the black, white flowers or designs in gold on a black ground, etc. About the same time an opaque-white cles. such as snuff-bottles, wine-cuns, etc.
when When Chienlung came to the throne, there became noticeable a decided change in the style of ornamenta-
tion, due probably to the influence of foreign designs, 
and especially to the importation of designs from Persia to be copied in China, or porcelain ordered from that country. It was at that time that European nobles and men of wealth conceived the idea of order
ing services of porcelain from China, bearing their ing services of porcelain from China, bearing their
family arms. The plates bearing the arms of Eng. family arms. The plates bearing the arms of Eing
land, France, and the Netherlands, still preserved at land, France, and the Netherlands, still preserved at reign, but the great majority are of later origin. reign, but the great majority are of later origin
Chienlung was succeeded by his son Chiaching (1796 1820), and all art languished under his feeble-minde rule, but under his second son, Taokuang (1821-1850)
in spite of internal difficulties caused by wars with France and England, some attention was given to th ceramic art, and the porcelain made for his own use compared favorably with that manufactured under some of his more worthy predecessors, and is at the present day much sought after by Chinese connois-
seurs.

The last period to be considered here included the years 1862 to 1874 , when T'ungchih was the Emperor The manufacture of porcelain was renewed, and great attention was paid to its improvement, and the same
remark applies to the next reign, which began in 1875 . Some of the decorations in sepia are of a high order of merit, another style which came much into favor consisting of flowers and butterflies in black and white on a pale turquois ground. But in more recent years the most marked advance has been made in the reproduction of the famille verte decoration-which was of K'and's reigng and of plum of the first black grounds.

ITALIAN ENDURANCE OF ARCTIC COLD.

THE narrative just issued by the Duke of Abruzzi, in which his Royal Highness gives his personal experiences of life and exploration in the Arctic zone, is the "Stella d degree of latitude yet reached, and wound up by the the hal relazionects of the Achile Cavalli Molinelli on from Dr. Cavalli Molinelli's report may not be unwel come.

To begin with, Italians have always shown them selves capable of enduring, not only a very high, but also a very low temperature-the latter fact made memorable by Baron Larrey, Surgeon-General to the Emperor Napoleon's "Grande Armee" in the disastrous retreat from Moscow in 1813, when, of all the contingents, Murat's 10,000 Neapolitans were found to have common to the whole army but even from the cold, which was as prolonged as it was intense. This ob-

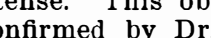
Cavalli Molinelli, according to whom the health of all on board the "Stella Polare" was excellent-the only exeeptions being the Duke himself and Commandant Cagni, whose scientific zeal so outran their prudence that they suffered severely from frost bite, resulting, n the commandant's case especially, in lesions affecting the hands and even costing him several fingers. in a number we the durty who folt greatly better than in a number of the party, who felt greatly better than habitually at home, they quite got rid they suffered Cot rid of, although cautions) from 15 or 18 degrees above zero in their

THE NAVAL WAR GAME BETWEEN THE UNITED STATES AND GERMANY.-IX.* By Fred T. JANE.

OPERATIONS OFF KIAO CHAU.

As already related, the German fleet retired to Kiac Chau, there to be blockaded by the American vessels. Americans to indicate that several German ships were so damaged at the Manila fight as to be now useless. As a matter of fact, however, this idea was only very partially correct. The "Kaiser Friedrich der Dritte" certainly needed repairs, but the main object of the Germans in allowing themselves to be blockaded was a strategical ruse. By means of it they secured a heavy initial advantage in ability to choose their own bunkers. As, however, the Americans were with full bunkers. As, however, the Americans were accomphave these fitted for coaling at sea, they too were enabled to keep their bunkers fairly full, and no ships had to be absent, as at off Santiago in the HispanoAmerican war. In one respect, therefore, the German
side drew a blank. They were waiting at Kiao Chau chusetts." Should speed be urgently needed, the American fleet was, therefore, in a position to detach a strong, swift force, one that roughly represented half

It may not be without interest at this juncture to compare the "Aeets by the rate values assigned to \& Co.) classification. U. S. Fleet.

3 "Maines," Rate I at 1.0 each....... $=3.0$ 1 "Alabama," Rate I at 1.0 each........ $=1.0$

2 "Indianas," Rate II at .8 each........

German Fleet.

"Wittelsbachs," Rate 1 at 1.0 each... $=2.0$

5 "Kaisers," Rate II at . 8 each........

1 "Bismarck," Rate II-III at .7 each..... $=\frac{.7}{6.7}$

Bearing in mind that the Americans had the ad vantage of two destroyers with them against the Ger-
man advantage of greater homogeneity of units, it

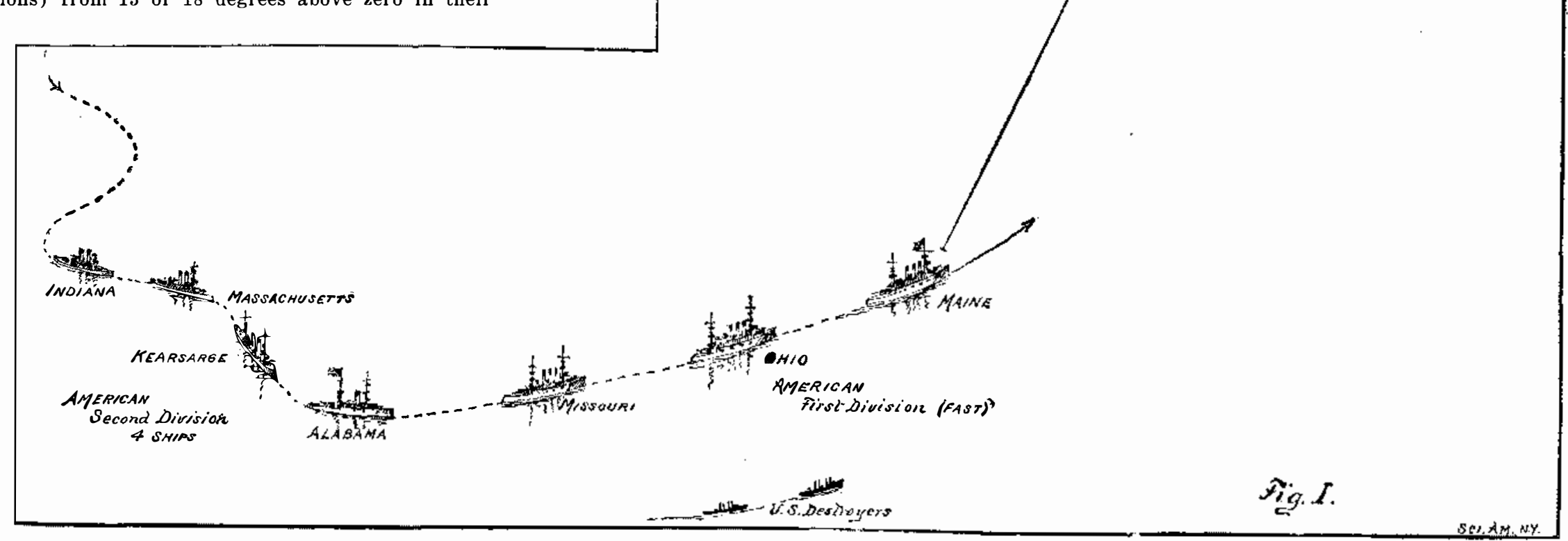

NAVAL WAR GAME. OPERATIONS OFF KIAO CHAU-FIRST STAGE.

tent to 35 or 40 degrees below it in the open. Dr. Cavalli Molinelli attributes this result to the absolute purity of the atmosphere without dust, and calls attention to the fact that more than one of these sudden and continuous desire to expectorate."

The rigorous limitation of fermented liquors in the dietary and the prohibition of distilled alcohol had als o their invariable effect in maintaining the health of the party. Dr. Cavalli Molinelli allowed no cognac,

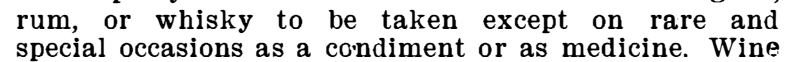
was conceded only in small quantity at supper-about. 120 grammes of "barolo" (a dark-red "blood-making" 120 grammes of "barolo" (a dark-red "blood-making" this regimen were conspicuous, he adds, the excellent hygienic conditions above referred to but also in the temper of the party, alacrity and cordiality always prevailing among the subalterns. Nor was it only among the Italian nationality that these effects were seen. The Norwegian contingent, inured more or less to the ingestion of alcohol, and using beer as
a constant beverage at home, were manifestly better a constant beverage at home, were manifestly better
for the abstention from these drinks, as practised on for the abstention from these drinks, as practised on
board the "Stella Polare" and on the sledge journeys.
- The Lancet. till one of the "Maine" class should be absent, and
for this they waited in vain. After a ten days' quiet(n) waited in vain. After a ten days' quietformed by two destroyers that were with them that

It came out in line ahead in the order indicated in the diagram. (In all these diagrams Kiao Chau lies to the right.) The two best ships, "Wittelsbach" and "Zaehringen," were at the head and tail of the line respectively; the weakest, the "Kaiser Frie and "Fürst Bismarck," occupied the center. "tail" be-
This formation of a line is good, a weak "tail be This formation of a line is good, a weak "tail" be-
ing the worst of drawbacks, since it invites attack in that quarter.

The American formation-order, from this point of view, was not so good. The ships were, however, dis posed to meet a different contingency, one in which squadrons were formed, the first of the three homogeneous and fast ships of the "Maine" class, the second of the remaining non-homogeneous and slower ships "Alabama," "Kearsarge," "Indiana," and "Massa-

* Prepared especially for the ScIENTIFIC AmERrcaN by the well-known
naval ex vert and inventor of the naval war game; with exclusive rights

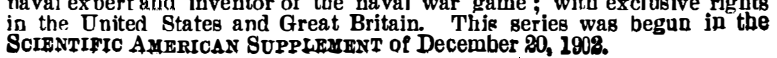

may be said that the flcets were as nearly equal as might be. In view of the issues at stake, neither side cared to join issue without some considerable tactical advantage at the start. An attempt to secure such an advantage led to the interesting though abortive evolutions under review. Special interest attaches to them because of the theory, now gaining ground so rapidly in most navies, that the battle of the future will be fought and won before range is reached and before a gun is fired. The fighting, by this theory, will mere determine the magnitude of the victory. The first tactical aim of each rival admiral was to concentrate on the tail of the enemy's line, a consum the Americans. In consequence (Diagram In) the two the Americans. In consequence (Diagram I.) the two 13,000 to 11,000 yards between the nearest ships. Fir. distance stood to be pure waste of ammunition, and neither side attempted it

The average German speed was considerably higher than that of the Americans, whose ships also made no attempt at top speed, doing $10 \% / 2$ knots while the Subsequently both sides increased speed somewhat, 